\title{
Farklı potasyum gübre formları ve oranlarının brokoli bitkisinin kadmiyum alımı üzerine etkileri
}

\section{Faruk ÖZKUTLU iD 1}

1Ordu Üniversitesi Ziraat Fakültesi Toprak Bilimi ve Bitki Besleme Bölümü, 52200, Altınordu/Ordu

Alınış tarihi: 1 Nisan 2020, Kabul tarihi: 5 Haziran 2020

Sorumlu yazar: Faruk ÖZKUTLU, e-posta: farukozkutlu@hotmail.com

\section{$\ddot{0} \mathbf{z}$}

Kadmiyum, yüksek konsantrasyonlarda bulunduğunda bitki, hayvan ve insanlara toksik etkisi olan bir elementtir. Toprak ve bitkilerde kadmiyumun (Cd) birikiminin olması nedeniyle dokularında $3 \mathrm{mg} \mathrm{kg-1'dan} \mathrm{fazla} \mathrm{Cd} \mathrm{içeren} \mathrm{bitkileri}$ düzenli olarak tüketen insanlarda Cd'un toksik etkileri görülmektedir. Bu nedenle, dünya genelinde topraklarda ve bitkilerde Cd'un birikiminin boyutları ve bitkilerde birikiminin azaltılmasına yönelik araştırmalar hızla artmaktadır. Bu araştırma, sera koşullarında brokoli (Brassica oleracea italica) bitkisine farklı potasyumlu $\left(\mathrm{KCl}, \mathrm{K}_{2} \mathrm{SO}_{4}\right.$ ve $\left.\mathrm{KNO}_{3}\right)$ gübrelerin 4 farklı dozda $(0,200,600$ ve $1800 \mathrm{mg} \mathrm{kg}$ 1) uygulanmasıyla bitkinin $\mathrm{Cd}$ alımı üzerine etkisi belirlenmiștir. Potasyumun $\mathrm{Cl}^{-}, \mathrm{NO}_{3}^{-}$ve $\mathrm{SO}_{4}^{-2}$ formlarında ve $\left(0,200,600\right.$ ve $\left.1800 \mathrm{mg} \mathrm{kg}^{-1}\right)$ uygulandığı dozlarda yeşil aksama Cd taşınması tüm dozlarda kontrole göre artmıştır. Artan dozlarda $\mathrm{KCl}$ uygulanmalarının tamamında $\mathrm{K}^{\prime}$ un $\mathrm{NO}_{3}^{-}$ve $\mathrm{SO}_{4}^{-2}$ formlarına göre kontrole göre kuru madde verimini azaltırken yeşil aksam Cd alımını arttırmıștır. Kadmiyumun $2.5 \mathrm{mg} \mathrm{kg}^{-1}$ ve K'un $1800 \mathrm{mg} \mathrm{kg}^{-1} \mathrm{Cl}^{-}$, $\mathrm{NO}_{3}{ }^{-}$ve $\mathrm{SO}_{4}^{-2}$ formları uygulandığında, kuru madde verimleri $2.3,2.41,2.36 \mathrm{~g} \mathrm{bitki}^{-1}$ olduğu ve yeşil aksam Cd alımlarının ise sırasıyla $23.9,18.4$ ve 17.9 mg $\mathrm{kg}^{-1}$ olduğu saptanmıștır. Bu araștırmada, $\mathrm{Cl}^{-}$ anyonunun $\mathrm{NO}_{3}{ }^{-}$ve $\mathrm{SO}_{4}^{-2}$ anyonlarına göre brokoli (Brassica oleracea italica) bitkisinin yeşil aksamında $\mathrm{Cd}$ alımının daha fazla olması muhtemelen $\mathrm{Cd}-\mathrm{Cl}$ kompleksinin $\mathrm{Cd}$ absorbsiyonuna katıldığını göstermektedir. Bu sonucunda da topraklarda $\mathrm{Cd}^{+2}$ 'nın biyoyararlığını artırmaktadır. Sonuç olarak, Cd kontamine olmuş topraklara potasyumlu gübre uygularken formların ve oranların dikkate alınması gerekliği belirlenmiştir.

Anahtar kelimeler: Potasyumlu gübreler, anyon, kadmiyum alımı, brokoli

Effects of different forms and ratios of potassium fertilizer on cadmium uptake of broccoli plant

\begin{abstract}
Cadmium, when present at high concentrations, is an element with toxic effect on plants, animals and humans. Cadmium toxicity is occurred in humans consuming regularly the plants containing $3 \mathrm{mg} \mathrm{kg}^{-1}$ in their tissues because of cadmium (Cd) accumulation in soil and plants. Therefore, studies regarding the extent of $\mathrm{Cd}$ accumulation and relevant precautions directed for decreasing its accumulation have increased rapidly in worldwide. This study, as a pot experiment in greenhouse conditions, was carried out to determine effect of different forms $\left(\mathrm{KCl}, \mathrm{K}_{2} \mathrm{SO}_{4}\right.$ and $\left.\mathrm{KNO}_{3}\right)$ and doses $(0,200,600$ and $1800 \mathrm{mg} \mathrm{kg}^{-1}$ in) of potassium fertilizer on $\mathrm{Cd}$ uptake. Cadmium transport to green parts has increased in all forms of $\mathrm{Cl}^{-}, \mathrm{NO}_{3}{ }^{-}$and $\mathrm{SO}_{4}{ }^{-2}$ and doses $\left(0,200,600\right.$ and $\left.1800 \mathrm{mg} \mathrm{kg}^{-1}\right)$ of potassium as compared to the control. All increasing $\mathrm{KCl}$ doses increased $\mathrm{Cd}$ accumulation by green parts while dry matter yield decreased in comparison to the $\mathrm{NO}_{3}$ and $\mathrm{SO}_{4}{ }^{-2}$ forms of K. With the application of $2.5 \mathrm{mg}$ $\mathrm{kg}^{-1} \mathrm{Cd}$ and $1800 \mathrm{mg} \mathrm{kg}^{-1} \mathrm{Cl}^{-}, \mathrm{NO}_{3}-$ and $\mathrm{SO}_{4}^{-2} \mathrm{~K}_{\text {forms, }}$ the dry matter yields and green parts $\mathrm{Cd}$ uptakes were found to be as the followings; $2.3,2.41,2.36 \mathrm{~g}$ plant ${ }^{-1}$ and $23.9,18.4$ and $17.9 \mathrm{mg} \mathrm{kg}^{-1}$, respectively.
\end{abstract}


In this study, higher $\mathrm{Cl}^{-}$anion in green parts of broccoli plant as compared to $\mathrm{NO}_{3}{ }^{-}$and $\mathrm{SO}_{4}{ }^{-2}$ anions shows that the $\mathrm{Cd}-\mathrm{Cl}$ complex presumably participates in $\mathrm{Cd}$ absorption. As a result of this, bioavailability of $\mathrm{Cl}^{+2}$ in soils is increased. In conclusion, it was determined that the forms and ratios should be taken into account when applying potassium fertilizers to $\mathrm{Cd}$ contaminated soils.

Key words: Potassium fertilizers, anion, cadmium uptake, broccoli

\section{Giriş}

Tarım topraklarında çok düşük de olsa kadmiyum (Cd) bulunmaktadır. Ancak, topraklardaki Cd içeriği doğal koşullarda oldukça düşük olmasına rağmen çeşitli kaynaklardan toprağa Cd girişi olabilmektedir. Kadmiyum, antroponejik kaynaklardan atmosfer yoluyla, tarım arazilerine kanalizasyon çamurunun uygulanması ve gübre kullanımı yoluyla topraklara Cd girişi olmakta ve birikilebilmektedir. Gübrelerden topraklara $\mathrm{Cd}$ girişi olmakta ve gübrelerin türüne göre Cd içerikleri farklılık göstermektedir (Kılıç ve Korkmaz 2012; Özkutlu ve Kara, 2018). Fosfor gübreleri $300 \mathrm{mg} \mathrm{Cd} \mathrm{kg}^{-1}$ üstünde Cd'a sahip olurken,

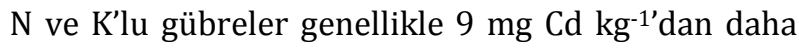
az Cd içermektedir (Fergusson, 1990). Genellikle N'lu ve K'lu gübrelerin ham madde kaynağının Cd içeriğinin $1 \mathrm{mg} \mathrm{kg}^{-1}$ dan daha düşük olduğu açıklanmıştır (Zarcinas and Nable 1992). Kadmiyum, tarımsal topraklarda birikebilen, bitkilere mutlak gerekli olmayan toksik bir ağır metaldir (Wu et al., 2016; Huang et al., 2018; Korkmaz ve ark., 2018). Tarımsal toprakların Cd kontaminasyonun boyutlarının belirlenmesi çalıșmaları artan bir hızla devam etmektedir. Bitkisel gidalarda $\mathrm{Cd}$ toksik sinırlarda birikebilmekte ve besin zinciriyle insanlara geçiși olmaktadır. Kadmiyum insan sağlı̆ı için potansiyel riskler oluşturmaktadır. İnsanlarda toksik düzeyde birikmesi sonucunda görme bozukluğu, yüksek tansiyon, akciğer, karaciğer ve böbrek rahatsızlıkları gibi ciddi sağlık problemlerine neden olmaktadır (Jarup et al., 1998; Boussen et al., 2013; Nie et al., 2016). Bu nedenle, Cd üzerine yapılan mevcut araştırmalar tarımsal ürünlerde $\mathrm{Cd}$ birikimini en aza indirgemek ve insan sağlığı üzerine risklerin hafifletilmesi üzerine yoğunlaşmıştır. Gübrelemenin tarım ürünlerinin üretiminin sürdürülmesi için vazgeçilmez bir faktör olduğu, ancak toprak-bitki sistemlerinde $\mathrm{Cd}$ taşınmasına ve birikimini de yol açtığı ileri sürülmektedir (Zhao et al.,2003; Cheng et al., 2018) . Toprakta potasyum bitkilerin mutlak gereksinim duyduğu bir makro element olup bitkiler tarafindan azottan sonra en fazla alınan besin elementlerinden biridir (Esençayı ve Korkmaz, 2019). Türkiye'de bitkisel ürünlerin yetiştirilmesi ve daha yüksek ve kaliteli ürün alabilmek için potasyumlu gübrelerin potasyum klorür (KCl), potasyum sülfat $\left(\mathrm{K}_{2} \mathrm{SO}_{4}\right)$ ve potasyum nitrat $\left(\mathrm{KNO}_{3}\right)$ formları yaygin olarak kullanılmaktadır (Korkmaz ve ark., 2015). Örneğin, Liu et al. (2013), K gübre uygulamasıyla misır yapraklarında $\mathrm{Cd}$ birikiminin arttığını açıklamıştır. Benzer şekilde yapılan başka bir araştırmada da potasyumun $\mathrm{KNO}_{3}$ ve $\mathrm{K}_{2} \mathrm{SO}_{4}$ formlarının haşhaş tohumunun $\mathrm{Cd}$ içeriğinde bir değişiklik göstermez iken KCl'nin Haşhaş tohumu Cd içeriğini artırdığını saptamıştır (Salardini et al., 1993). Toprak bitki sistemlerinde potasyum gübrelerdeki klorür $\left(\mathrm{Cl}^{-}\right)$, sülfat gibi anyonlar $\left(\mathrm{SO}^{-2}\right)$ ve $\mathrm{NO}_{3}{ }^{-} \mathrm{Cd}$ translokasyonunu etkilemektedir. Bazı araştırmalar $\mathrm{Cl}^{-}$anyonunun ve SO4-2 anyonuna göre bitkiler tarafından Cd alımı üzerine daha fazla etki ettiğini ileri sürmektedir. Toprak tuzluluğunun bitkilerde $\mathrm{Cd}$ birikimini etkileyen önemli bir faktör olduğu çeşitli araştırıcılar tarafından ortaya konmuştur (McLaughlin et al., 1998 a, b; Norvell et al., 2000; Özkutlu ve ark., 2007; Özkutlu ve Kara, 2019). ABD'de yapılan çalışmalarda topraklarda tuzluluğun artışıyla (özellikle Cl konsantrasyonunun artışıyla) bitkilerde Cd miktarının arttığı saptanmıştır (Norvell et al., 2000). Smolders and McLaughlin (1996), $\mathrm{CdCln}^{2-n}$ komplekslerinin $\mathrm{Cd}^{+2}$ ve $\mathrm{Cl}^{-}$anyonlariyla ilişkili olduğu ve bitkiler tarafından Cd'un oluşan kompleksleri kolayca almaktadır. Sülfat anyonlarının $\mathrm{Cl}^{-}$anyonları kadar kararlı $\mathrm{CdCln}^{2-\mathrm{n}}$ kompleksleri oluşturmamaktadır. $\mathrm{Bu}$ nedenle, $\mathrm{SO}^{2-}$ ve $\mathrm{Cl}^{-}$ bitkilerin Cd alımı üzerinde farklı etkilere sahiptir. Liu et al. (2003), Cd'nin birikiminin etkilerinin bitki organları, türleri ve çeşitler arasında farklı olduğu açıklamıştır. Smolders et al. (1998), toprakda tuzluluğun $\mathrm{NaCl}$ olarak artırılmasıyla toprak çözeltisinde çözünür $\mathrm{Cd}$ konsantrasyonunun 65 nM'dan 400 nM'a yükseldiğini buna karşın $\mathrm{NaCl}$ yerine $\mathrm{NaNO}_{3}$ uygulanması durumunda ise toprak çözeltisindeki çözünür Cd miktarında herhangi bir değişikliğin olmadığını belirlemiştir. Somolders and McLaughlin (1996), toprak çözeltisinde $\mathrm{Cd}^{+2}$ iyonunun $\mathrm{Cl}^{-}$ile $\mathrm{CdCl}_{n}{ }^{2-n}$ şeklinde bilinmeyen bir kompleks formu oluşturduğunu ve bu formun bitkilerce alınabildiğini ileri sürmüştür. Günümüzde fosforlu gübrelerin topraklara $\mathrm{Cd}$ girişi ve bitkilerde birikmesi üzerine çalışmalar yaygın iken potasyumlu gübrelerin bitkilerin $\mathrm{Cd}$ alımı üzerine olan etkilerine 
yönelik araştırmalar sınırlıdır. Bu nedenle, farklı ürünlerde $\mathrm{K}$ gübrelemesi ile $\mathrm{Cd}$ birikimi arasındaki ilişki hakkında çok fazla bilgi olmaması nedeniyle farklı kimyasal gübrelere bitkilerin $\mathrm{Cd}$ birikimi üzerine ilişkili olup olmadığı belirsizliğini korumaktadır. $\mathrm{Bu}$ araştırmada, Potasyumlu gübrelerin formları ve $\mathrm{Cd}$ arasındaki etkileşimleri ortaya çıkarılmıştır. Brokoli (Brassica oleracea italica) bitkisinde üç farklı $\mathrm{K}$ gübresinin $\left(\mathrm{KCl}, \mathrm{K}_{2} \mathrm{SO}_{4}\right.$ ve $\mathrm{KNO}_{3}$ ) $\mathrm{Cd}$ alımı üzerindeki etkileri belirlenmiştir.

\section{Materyal ve Yöntem}

Araştırma, sera koşullarında tesadüf parselleri deneme deseninde yürütülmüştür. Denemede test bitkisi olarak brokoli bitkisi yetiştirilmiștir. Uygulama dozları olarak sırasıyla; potasyumlu gübrelerin $\mathrm{KCl}, \mathrm{KNO}_{3}$ ve $\mathrm{K}_{2} \mathrm{SO}_{4}$ formları dört $(0,200$, 600 ve $\left.1800 \mathrm{mg} \mathrm{kg}^{-1}\right)$ ve (Cd) dozu ve $\mathrm{Cd}(0.1,0.5$ ve $2.5 \mathrm{mg} \mathrm{Cd} \mathrm{kg}^{-1}$ ) dozları altında 4 tekerrürlü olacak şekilde 108 saksıda yürütülmüştür.

\section{Denemede toprağının analizinde kullanılan yöntemler ve değerleri}

Toprak tekstürü (Bouyoucous, 1952) Killi Tın, pH (Jackson, 1959) 8.08, Organik Madde; Walkey-Black yaş yakma metoduyla (Jackson, 1959) \%0.7, Kireç (Çağlar, 1949) \%14.2, toprak tuzluluğu (U.S. Salinity Laboratory Staff, 1954) 0.22 mmhos/cm, DTPA'da ekstakte edilebilir $\mathrm{Zn}, \mathrm{Fe}, \mathrm{Cu}, \mathrm{Mn}$ ve $\mathrm{Cd}$ (Lindsay and Norvell, 1978) sirasiyla $0.1,2.33,0.44,2.70$ ve 0.005 $\mathrm{mg} \mathrm{kg}^{-1}$, Toplam Cd (Schlichting and Blume, 1966) $0.27 \mathrm{mg} \mathrm{kg}^{-1}$, yarayışlı $\mathrm{P}$ konsantrasyonu (Olsen, 1954) $4.13 \mathrm{mg} \mathrm{kg}^{-1}, \mathrm{~K}$ konsantrasyonu amonyum asetat (pH: $7.1 \mathrm{~N}$ ) yöntemine göre $244 \mathrm{mg} \mathrm{kg}^{-1}$ olarak belirlenmiștir.

\section{Sera denemesinin yürütülmesi}

Denemede polietilen 6 numaralı saksılar kullanılmış olup her saksıya 4 mm'lik elekten geçirilmiş $1.65 \mathrm{~kg}$ hava kuru toprak konulmuştur. Brokoli fidelerinin saksılara şaşırtılmadan önce temel gübrelemede azot için $\left(\mathrm{CaNO}_{3}\right)_{2} .4 \mathrm{H}_{2} \mathrm{O}$ formundan $200 \mathrm{mg} \mathrm{kg}^{-1} \mathrm{~N}$, fosfor için $\mathrm{CaHPO}_{4}$ formundan $100 \mathrm{mg} \mathrm{P} \mathrm{kg}{ }^{-1}$, kükürt için $\mathrm{CaSO}_{4}$ formundan $20 \mathrm{mg} \mathrm{kg}^{-1} \mathrm{~S}$, Fe-EDTA formunda $2.5 \mathrm{mg} \mathrm{kg}^{-1} \mathrm{Fe}$, çinko için $\mathrm{ZnSO}_{4} .7 \mathrm{H}_{2} \mathrm{O}$ formundan 1 $\mathrm{mg} \mathrm{kg}^{-1} \mathrm{Zn}$ uygulanmıştır. Denemede saksıların tamamında $\mathrm{N}$ dozları eşit olacak şekilde hesaplanıp uygulanmıştır. Brokoli fideleri saksılara şaşırtılmadan önce potasyumlu gübrelerin üç formu $\mathrm{KCl}\left(0,200,600\right.$ ve $\left.1800 \mathrm{mg} \mathrm{kg}^{-1}\right), \mathrm{KNO}_{3}(0,200,600$ ve $\left.1800 \mathrm{mg} \mathrm{kg}^{-1}\right)$ ve $\mathrm{K}_{2} \mathrm{SO}_{4}(0,200,600$ ve $1800 \mathrm{mg}$ $\mathrm{kg}^{-1}$ ) dozlarıyla üç Cd dozu (Cd $0.1=0.1 \mathrm{mg} \mathrm{Cd} \mathrm{kg}^{-1}$, $\mathrm{Cd} 0.5=0.5 \mathrm{mg} \mathrm{Cd} \mathrm{kg}^{-1}$ ve $\mathrm{Cd} 2.5=2.5 \mathrm{mg} \mathrm{Cd} \mathrm{kg}^{-1}$ )
$3 \mathrm{CdSO}_{4} .8 \mathrm{H}_{2} \mathrm{O}$ formundan uygulanmıştır. Kimyasal gübreler karıștırıldıktan sonra fidelerden 5-6 cm büyüklüğünde homojen olanlardan her saksıya 3 adet dikilmiş ve ardından 4 gün sonra 2 bitki kalacak şekilde seyreltilmiştir. Bitkiler saf suyla günlük olarak tarla kapasitesine yakın bir nem içeriğinde olacak şekilde sulanmıştır. Sera koşullarında 28 gün büyütülüp çiçeklenme öncesinde toprak üstünden 2$3 \mathrm{~cm}$ yukarıdan hasat edilmiştir. Hasat edilen bitkiler yeşil aksam kuru madde veriminin belirlenmesi için $70{ }^{\circ} \mathrm{C}^{\prime}$ de 48 saat kurutulmuştur. Kuru madde verimleri ( $\mathrm{g}$ bitki ${ }^{-1}$ ) olarak saptanmıştır.

\section{Bitki analizleri}

Kurutulan bitki örnekleri ağırlıkları alındıktan sonra agat taşa sahip değirmende öğütülmüştür. Yeşil aksam örneklerinde 0.25 gram tartılarak $2 \mathrm{ml}$ saf su, $2 \mathrm{ml} \mathrm{H} \mathrm{O}_{2}$ (\%30'luk) ve $4 \mathrm{ml} \mathrm{HNO}_{3}$ (\%65'lik) içeren bir karışımı içinde mikro dalga cihazında yakılmıştır (CEM MARS X-PRESS ). Yakılan örnekler oda sıcaklığına kadar soğutulduktan sonra saf su ile 25 ml'ye tamamlanarak mavi bant filtre kağıdından süzülmüștür. Süzüklerde $\mathrm{K}, \mathrm{P}, \mathrm{Mg}, \mathrm{Zn}, \mathrm{Fe}, \mathrm{Cu}, \mathrm{Mn}$ ve Cd konsantrasyonları ICP cihazında Inductively Coupled Plasma-Atomik Emission Spectrometry, VARIAN VISTA PRO) cihazında ölçülmüştür. Elde edilen verilerin excell paket programı kullanılarak standart sapmaları belirlenmiştir. Elde edilen veriler dört tekrarlamalı olarak çizelgelerde (ortalama \pm standart hata) şeklinde verilmiştir.

\section{Bulgular ve Tartışma}

Potasyumlu gübrelerin farklı formlarının artan (0, 200, 600, $\left.1800 \mathrm{mg} \mathrm{kg}^{-1}\right)$ ve artan Cd'un (0.1, 0.5 ve $2.5 \mathrm{mg} \mathrm{kg}^{-1}$ ) dozlarının birlikte uygulanmasıyla brokoli yeșil aksam kuru madde verimlerinde önemli farklılıkların olduğu tespit edilmiştir (Çizelge 1). Artan Cd dozlarının hepsinde $\mathrm{KCl}$ formunun $(0,200$, $600,1800 \mathrm{mg} \mathrm{kg}^{-1}$ ) uygulanmasiyla kuru madde veriminde önemli azalmalar meydana gelmiştir. Örneğin, toprağa $2.5 \mathrm{mg} \mathrm{Cd} \mathrm{kg-1}$ uygulamasında kontrolde kuru madde verimi $3.0 \mathrm{~g} \mathrm{bitki}^{-1}$ iken artan $\mathrm{KCl}$ uygulamalarında sırasıyla 3.05, 2.57, $2.13 \mathrm{~g}$ bitki- $^{-}$ 1 düzeyine gerilediği belirlenmiştir. $0.5 \mathrm{mg} \mathrm{Cd} \mathrm{kg}^{-1}$ uygulamasının kontrolde $3.65 \mathrm{~g}^{\text {bitki }}{ }^{-1}$ kuru madde verimi elde edilmiş iken $\mathrm{K}^{\prime} \mathrm{un} \mathrm{Cl}^{-}$formunun artan dozlarda uygulamalarında $3.23,2.84$ ve $2.54 \mathrm{~g} \mathrm{bitki}^{-1}$ olduğu bulunmuştur (çizelge 1). Kuru madde verimlerindeki azalmalar $\mathrm{NO}_{3}$ - ve $\mathrm{SO}_{4}^{-2}$ formunda da benzer sonuçlar göstermiş olup ancak, $\mathrm{Cl}^{-}$formuna göre kuru madde verimini azaltmaları daha az olmuştur. 
Çizelge 1. Farklı Dozlarda Cd ile kontamine edilmiş toprakta farklı potasyum formlarının artan oranlarda uygulamasının brokoli yeşil aksam kuru madde verimi üzerine etkisi

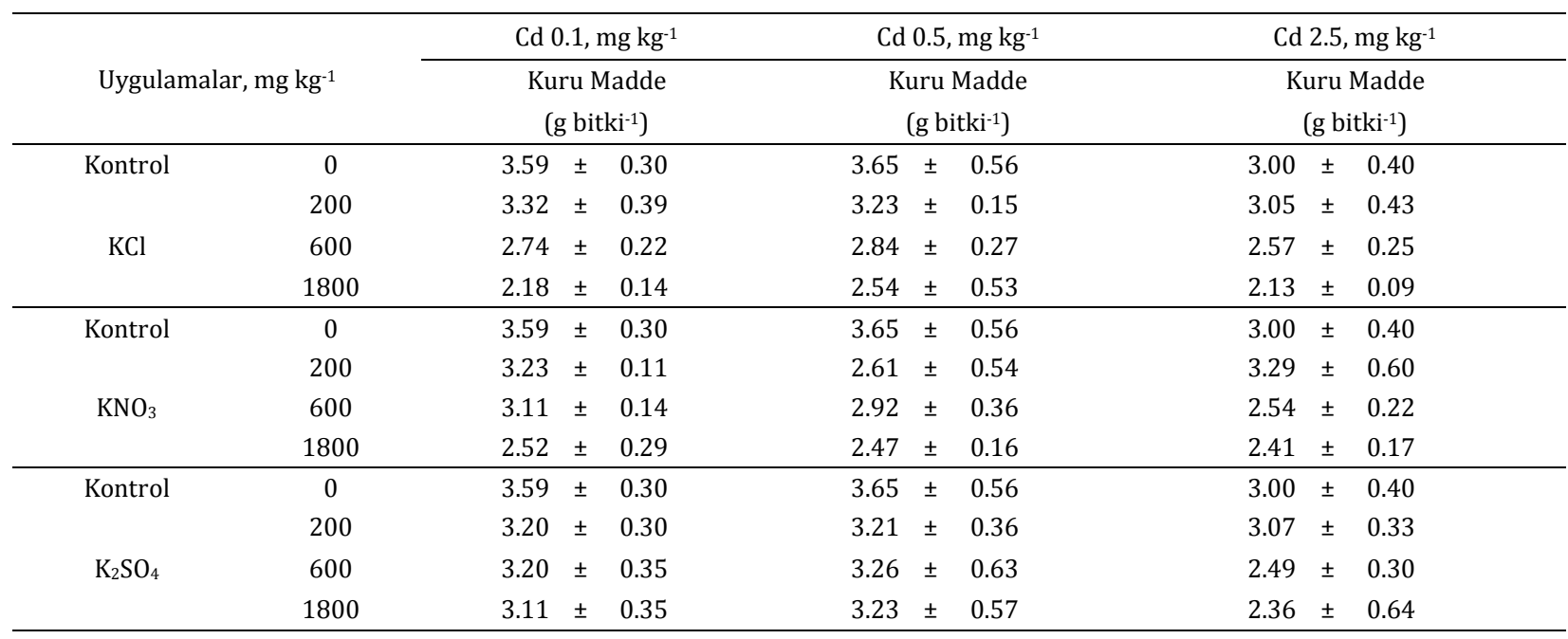

\section{Yeşil aksam Cd konsantrasyonu}

Potasyumlu gübrelerin $\mathrm{Cl}^{-}$, $\mathrm{NO}_{3}^{-}$ve $\mathrm{SO}_{4}^{-2}$ formları $\operatorname{artan}\left(0,200,600\right.$ ve $\left.1800 \mathrm{mg} \mathrm{kg}^{-1}\right)$ dozlarının Cd'un $\left(0.1,0.5\right.$ ve $\left.2.5 \mathrm{mg} \mathrm{Cd} \mathrm{kg}^{-1}\right)$ dozlarına uygulanmasıyla brokoli bitkisinin Cd alımlarında önemli farklılıkların olduğu tespit edilmiştir. Toprağın çok düşük bir

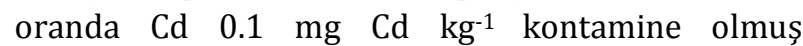
durumuma potasyumun formlarının $\mathrm{Cl}, \mathrm{NO}_{3}{ }^{-}$ve $\mathrm{SO}_{4}^{-2}$ anyonlarının uygulanması sonucunda kontrol bitkisinde $\mathrm{Cd} 1.2 \mathrm{mg} \mathrm{kg}^{-1}$ iken anyonların artan dozlarında sırasıyla $\mathrm{KCl}$ için; $1.4,1.6,1.8, \mathrm{KNO}_{3}$ için; 1.2, 1.2, 1.3 ve $\mathrm{K}_{2} \mathrm{SO}_{4}$ için $1.3,1.3,1.2 \mathrm{mg} \mathrm{kg}^{-1}$ olduğu bulunmuştur (çizelge 2). Toprak çok düşük miktarda $\mathrm{Cd}$ ile kontamine olduğunda potasyumun $\mathrm{NO}_{3}{ }^{-}$ve $\mathrm{SO}_{4}{ }^{-2}$ formunun brokoli yeșil aksamında Cd alımında artışa neden olmadığı belirlenmiş ve bu durumun azot (N) birincil ve kükürt (S)'unde ikincil besin elementleri olmasından ileri geldiği düşünülmektedir. Potasyumun $\mathrm{Cl}^{-}$anyonun $1800 \mathrm{mg}$ $\mathrm{kg}^{-1}$ uygulamasında ise kontrolde Cd alımı $1.2 \mathrm{mg} \mathrm{kg}^{-1}$ iken \%50 oranında $\mathrm{Cd}$ alımında artış sağladığı belirlenmiştir. Benzer eğilim toprakta $2.5 \mathrm{mg} \mathrm{Cd} \mathrm{kg}^{-1}$ ile kontamine olması durumunda da potasyumun $\mathrm{Cl}^{-}$, $\mathrm{NO}_{3}{ }^{-}$ve $\mathrm{SO}_{4}^{-2}$ formları arasında $\mathrm{Cl}$ - diğerlerine göre daha fazla $\mathrm{Cd}$ taşıdığı görülmektedir. Toprak $2.5 \mathrm{mg}$ $\mathrm{Cd} \mathrm{kg}^{-1}$ kirlenmiş durumda kontrolde yeșil aksam Cd alımı $17.6 \mathrm{mg} \mathrm{kg}{ }^{-1}$ iken $1800 \mathrm{mg} \mathrm{KCl} \mathrm{kg}{ }^{-1}$ uygulanmasında $23.9 \mathrm{mg} \mathrm{kg}^{-1}$ düzeyinde olduğu ve \%35.8 oranında $\mathrm{Cd}$ alımında artış olduğu saptanmıştır (çizelge 2). Bitkinin yeșil aksamındaki Cd konsantrasyonunu etkilemede $\mathrm{Cl}^{-}$tuzlarının NO3ve $\mathrm{SO}_{4}^{-2}$ tuzlarına göre daha büyük rol oynadığı saptanmıştır. Farklı oranlarda $\mathrm{Cd}$ ile kontamine edilmiş topraklarda artan dozlarda $\mathrm{KCl}$ uygulanmasıyla bitkilerin $\mathrm{Cd}$ konsantrasyonunda belirgin artışlar olmuştur.

\section{Yeşil Aksam Mineral Element Konsantrasyonu}

Toprağın Cd'un $\left(0.1,0.5\right.$ ve $\left.2.5 \mathrm{mg} \mathrm{kg}^{-1}\right)$ dozlarıyla kontamine edilmesiyle potasyumlu gübrele formlarının $\operatorname{artan}\left(0,200,600,1800 \mathrm{mg} \mathrm{kg}^{-1}\right)$ dozlarının uygulanmasıyla yeşil aksam $\mathrm{K}, \mathrm{P}$ ve $\mathrm{Mg}$ konsantrasyonlarında değişikliklerin olduğu tespit edilmiştir. Potasyumlu gübrelerin artan dozlarının uygulanmasıyla $\mathrm{P}$ ve $\mathrm{Mg}$ konsantrasyonlarında önemli değişiklik olmaz iken $\mathrm{K}$ konsantrasyonları artmıştır. En yüksek doz olan $2.5 \mathrm{mg} \mathrm{Cd} \mathrm{kg}^{-1}$ ve 1800 mg kg-1 dozlarının $\mathrm{Cl}^{-}, \mathrm{NO}_{3}{ }^{-}$ve $\mathrm{SO}_{4}{ }^{-2}$ uygulanmasıyla sirasiyla kontrolde \%4,16'dan \%5,41'e, 4,16'dan 5,17'e, 4.16'dan 5.02'e yükseldiği saptanmıştır (çizelge3).

Toprağın Cd'un $\left(0.1,0.5\right.$ ve $\left.2.5 \mathrm{mg} \mathrm{kg}^{-1}\right)$ dozlarıyla kontamine edilmesiyle potasyumlu gübrele formlarının $\operatorname{artan}\left(0,200,600,1800 \mathrm{mg} \mathrm{kg}^{-1}\right)$ dozlarının uygulanmasıyla yeşil aksam $\mathrm{Zn}, \mathrm{Fe}, \mathrm{Cu}$ ve Mn konsantrasyonlarında değişikliklerin olduğu tespit edilmiştir. Sonuçlardan görüldüğü gibi yeşil aksam $\mathrm{Fe}, \mathrm{Cu}, \mathrm{Mn}$ konsantrasyonlarında önemli bir değişikliği olmadığı ancak Cd alımının fazla olduğu yerlerde $\mathrm{Zn}$ taşınımlarında farklılıkların olduğu görülmüştür (çizelge 4). Bu durum da düşük $\mathrm{Cd}$ içeriğine sahip toprakta Zn'nun bitkide Cd alımını engellediği buna karşı yüksek $\mathrm{Cd}$ konsantrasyonuna sahip olan toprakta ise arttırmasıyla açıklanabilir. 
Çizelge 2. Farklı Dozlarda Cd ile kontamine edilmiş toprakta farklı potasyum formlarının artan oranlarda uygulamasının brokoli yeşil aksam Cd alım miktarı üzerine etkisi

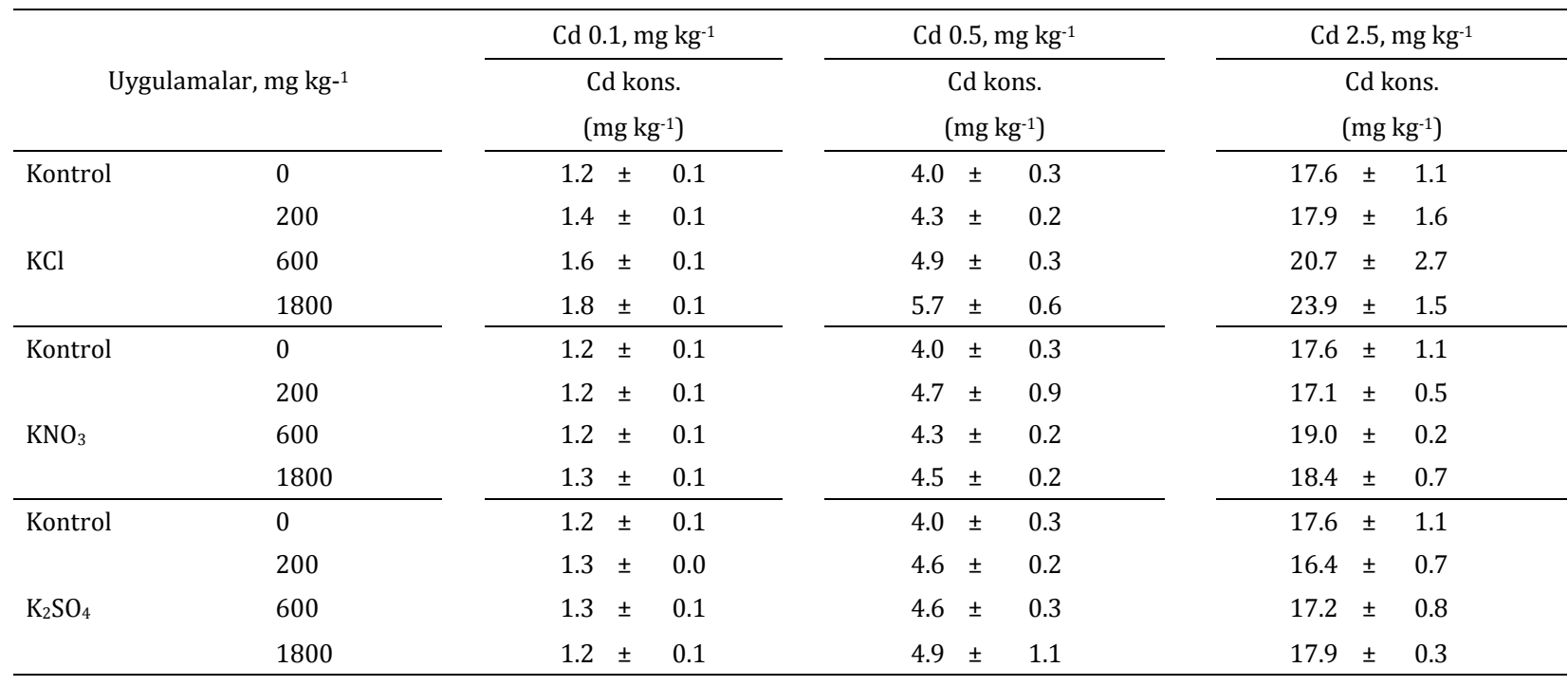

Çizelge 3. Farklı Dozlarda Cd ile kontamine edilmiş topraklarda farklı potasyum formlarının artan oranlarda uygulamasının brokoli yeşil aksam $\mathrm{K}, \mathrm{P}$ ve Mg alım miktarı üzerine etkisi.

\begin{tabular}{|c|c|c|c|c|c|c|c|c|c|c|}
\hline \multirow{2}{*}{\multicolumn{2}{|c|}{ Uygulamalar, mg kg-11 }} & \multicolumn{3}{|c|}{$\mathrm{Cd} 0.1, \mathrm{mg} \mathrm{kg}^{-1}$} & \multicolumn{3}{|c|}{$\mathrm{Cd} 0.5, \mathrm{mg} \mathrm{kg}^{-1}$} & \multicolumn{3}{|c|}{$\mathrm{Cd} 2.5, \mathrm{mg} \mathrm{kg}^{-1}$} \\
\hline & & $\mathrm{K}$ & $\frac{\mathrm{P}}{(\%)}$ & $\mathrm{Mg}$ & K & $\begin{array}{l}\mathrm{P} \\
(\%)\end{array}$ & $\mathrm{Mg}$ & $\mathrm{K}$ & $\frac{P}{(\%)}$ & $\mathrm{Mg}$ \\
\hline \multirow[t]{2}{*}{ Kontrol } & 0 & 3.79 & 0.45 & 0.56 & 4.03 & 0.50 & 0.50 & 4.16 & 0.46 & 0.53 \\
\hline & 200 & 5.10 & 0.49 & 0.52 & 4.99 & 0.49 & 0.49 & 4.88 & 0.44 & 0.46 \\
\hline \multirow[t]{2}{*}{$\mathrm{KCl}$} & 600 & 4.84 & 0.49 & 0.53 & 5.16 & 0.47 & 0.47 & 5.00 & 0.43 & 0.46 \\
\hline & 1800 & 4.21 & 0.50 & 0.49 & 4.63 & 0.48 & 0.48 & 5.41 & 0.48 & 0.49 \\
\hline \multirow[t]{2}{*}{ Kontrol } & 0 & 3.79 & 0.45 & 0.56 & 4.03 & 0.50 & 0.50 & 4.16 & 0.46 & 0.53 \\
\hline & 200 & 4.27 & 0.47 & 0.50 & 4.52 & 0.48 & 0.48 & 4.62 & 0.47 & 0.50 \\
\hline \multirow[t]{2}{*}{$\mathrm{KNO}_{3}$} & 600 & 4.62 & 0.47 & 0.48 & 4.87 & 0.45 & 0.45 & 4.94 & 0.48 & 0.49 \\
\hline & 1800 & 4.65 & 0.50 & 0.50 & 4.95 & 0.48 & 0.48 & 5.17 & 0.49 & 0.47 \\
\hline \multirow[t]{2}{*}{ Kontrol } & 0 & 3.79 & 0.45 & 0.56 & 4.03 & 0.50 & 0.50 & 4.16 & 0.46 & 0.53 \\
\hline & 200 & 4.46 & 0.45 & 0.50 & 4.68 & 0.44 & 0.44 & 4.66 & 0.45 & 0.49 \\
\hline \multirow[t]{2}{*}{$\mathrm{K}_{2} \mathrm{SO}_{4}$} & 600 & 4.72 & 0.47 & 0.61 & 4.33 & 0.46 & 0.46 & 4.89 & 0.46 & 0.46 \\
\hline & 1800 & 4.86 & 0.49 & 0.67 & 5.04 & 0.48 & 0.48 & 5.02 & 0.49 & 0.48 \\
\hline
\end{tabular}

Tarım topraklarında müsaade edilebilir $\mathrm{Cd}$ konsantrasyonu $3 \mathrm{mg} \mathrm{kg}^{-1}$ olup, genelde topraklarda Cd düzeyi $0.1 \mathrm{mg} \mathrm{kg}^{-1}$ civarındadır (Alloway, 1995). $\mathrm{Bu}$ araștırmada artan oranlarda $(0.1,0.5$ ve $2.5 \mathrm{mg}$ $\mathrm{Cd} \mathrm{kg}^{-1}$ ) toprak Cd ile kontamine olduğunda brokoli yeşil aksam Cd alımı sırasıyla 1.2 , 4.0 ve $17.6 \mathrm{mg} \mathrm{kg}^{-1}$ düzeyinde olduğu tespit edilmiştir. $\mathrm{Bu}$ sonuçlardan görüldüğü gibi kirlilik boyutlarına göre Cd çok kolay bir şekilde taşınmaktadır. McBride (2003), topraklara kanalizasyon atıkları ve gübrelerle önemli miktarlarda Cd giriși olduğunu ve bu alanlarda yetişen (özellikle yaprakları yenen) sebzelerde Cd'un yüksek oranlarda biriktiğini açıklamıştır. $\mathrm{Bu}$ araştırmada bitkiye taşınmanın boyutları potasyum gübrelerin $\mathrm{Cl}^{-}, \mathrm{NO}_{3}^{-}$ve $\mathrm{SO}_{4}^{-2}$ formlarından özellikle $\mathrm{Cl}^{-}$ anyonunun daha da teşvik ettiği belirlenmiştir. Klor anyonun bitkiler tarafından $\mathrm{Cd}$ alımını teşvik ettiğine yönelik çeşitli araştırmalar bulunmaktadır. Elde ettiğimiz sonuçlara göre topraktaki tuzluluğun (özellikle klorürün) bitkilerde $\mathrm{Cd}$ birikimini etkileyen en önemli faktör olduğu ve $\mathrm{Cl}^{-}$anyonlarının toprak çözelti ortamında yaptığı kompleksler sonucunda Cd'un katyon değiștirici yüzeylere tutunması azalmakta ve böylece bitkilerce alınma 
şansının daha fazla olduğu düşünülmektedir. McLaughlin et al. (1997), patates yumrusundaki Cd konsantrasyonu ile toprak çözeltisi $\mathrm{Cd}^{+2}$ iyonu aktivetisi arasında bir ilişkinin olmadığını buna karşılık toprak çözeltisinin $\mathrm{Cl}$ kompleksleri ile yumru Cd konsantrasyonu arasında bir olumlu ilişkinin bulunduğunu ve artan $\mathrm{Cl}$ konsantrasyonuyla yumru Cd konsantrasyonunun arttığını belirlemiştir. Smolders et al. (1998), toprakda tuzluluğun $\mathrm{NaCl}$ olarak artırılmasıyla toprak çözeltisinde çözünür $\mathrm{Cd}$ konsantrasyonunun $65 \quad$ nM'dan $400 \quad$ nM'a yükseldiğini buna karşın $\mathrm{NaCl}$ yerine $\mathrm{NaNO}_{3}$ uygulanması durumunda ise toprak çözeltisindeki çözünür Cd miktarında herhangi bir değişikliğin olmadığını belirlemiştir. Birleșik Amerika'da yapılan bir çalıșmada, ayçiçeği çekirdeğinde Cd miktarının $\mathrm{Cl}^{-}$konsantrasyonunun artışıyla arttığı, buna karşın $\mathrm{SO}_{4}^{-2}$ 'in $\mathrm{Cd}$ konsantrasyonunu etkilemediği bildirilmiştir (Li ve ark., 1994). Zhong-Qiu et al. (2003), yaptığı araştırmada, sera koşullarında toprağa eşit oranda $\mathrm{K}^{\prime}$ un $\mathrm{NO}_{3}, \mathrm{SO}_{4}$ ve $\mathrm{Cl}^{-}$tuzlarının uygulamasıyla yazlık buğday yetiştirmiştir. Elde edilen bulgulara göre, buğday bitkisinin yeşil aksamında $\mathrm{Cl}^{-}$ve $\mathrm{SO}_{4}^{-2}$ anyonları $\mathrm{Cd}$ alımını arttırmaktadır.

$\mathrm{Bu}$ araștırmanın ve literatürde yapılmış araştırmaların sonuçlarından da görüldüğü gibi, farklı oranlarda Cd kirlenmesine maruz kalan topraklarda yetișen bitkilerde Cd'un kolaylıkla akümüle olduğu ve besin zinciri yoluyla Cd'un insanlara geçtiği bilinmektedir. Bu nedenle, birçok ülke, bitkisel ürünlerde maksimum izin verilebilir $\mathrm{Cd}$ limitlerini yasal düzenlemelerle ortaya koymuştur. Dokularında $3 \mathrm{mg} \mathrm{kg}^{-1^{\prime}}$ dan fazla Cd içeren bitkileri düzenli olarak tüketen insanlarda Cd'un toksik etkileri görülmektedir (Alloway, 1995). Bu nedenle, son yıllarda çeşitli bitkilerin $\mathrm{Cd}$ biriktirme kapasiteleri belirlenmesi, bünyesinde daha az $\mathrm{Cd}$ biriktiren çeşitlerin geliştirmesi ve bitkilerin $\mathrm{Cd}$ alımlarını arttırıcı/azaltıcı faktörlerin ortaya konulmasına yönelik çalışmalara hız verilmiştir. Beslenmemizde büyük rol oynayan buğday, mısır, çeltik, marul, bezelye, brokoli, pancar, turp ve patates Cd'u kolayca absorbe edebilmektedir. Topraklardaki Cd konsantrasyonu düşük olmasına rağmen, insan beslenmesinde önemli rol oynayan buğday, mısır, çeltik gibi tahıllarda ve sebzelerde yüksek miktarlarda Cd birikebilmektedir. Yumru köke sahip ve yaprağı yenen sebzelerde kadmiyum birikimi diğer bitki türlerine göre daha fazla olmaktadır (Jinadsa et al., 1997). Patates, misır, fasulye ve bezelyenin çok az miktarda $\mathrm{Cd}$ akümüle ettiği buna karşılık salatalık, ıspanak, kereviz, brokoli ve lahananın fazla miktarda Cd'u biriktirebilme özelliğine sahip olduğu açıklanmıştır (Bergman, 1992; Wang et al., 2009; Zhang et al., 2013). Bitkilerin yenilebilir kısımlarına taşınan Cd miktarı türler arasında önemli düzeyde farklılık göstermektedir.

Çizelge 4. Farklı Dozlarda Cd ile kontamine edilmiş topraklarda farklı potasyum formlarının artan oranlarda uygulamasının brokoli yeșil aksam $\mathrm{Zn}, \mathrm{Fe}, \mathrm{Cu}$ ve $\mathrm{Mn}$ alım miktarları üzerine etkisi

\begin{tabular}{|c|c|c|c|c|c|c|c|c|c|c|c|c|c|}
\hline \multirow{2}{*}{\multicolumn{2}{|c|}{$\begin{array}{l}\text { Uygulamalar, } \\
\text { mg kg-1 }\end{array}$}} & \multicolumn{4}{|c|}{$\mathrm{Cd} 0.1, \mathrm{mg} \mathrm{kg}-1$} & \multicolumn{4}{|c|}{$\mathrm{Cd} 0.5, \mathrm{mg} \mathrm{kg}-1$} & \multicolumn{4}{|c|}{$\mathrm{Cd} 2.5, \mathrm{mg} \mathrm{kg}-1$} \\
\hline & & $\mathrm{Zn}$ & $\mathrm{Fe}$ & $\mathrm{Cu}$ & $\mathrm{Mn}$ & $\mathrm{Zn}$ & $\mathrm{Fe}$ & $\mathrm{Cu}$ & $\mathrm{Mn}$ & \multirow{2}{*}{$\begin{array}{l}\mathrm{Zn} \\
20\end{array}$} & \multirow{2}{*}{$\begin{array}{l}\mathrm{Fe} \\
49\end{array}$} & \multirow{2}{*}{$\begin{array}{c}\mathrm{Cu} \\
3,9\end{array}$} & \multirow{2}{*}{$\begin{array}{l}\mathrm{Mn} \\
201\end{array}$} \\
\hline Kontrol & 0 & 22 & 65 & 5,6 & 198 & 23 & 80 & 4,8 & 219 & & & & \\
\hline & 200 & 23 & 65 & 5,4 & 185 & 21 & 64 & 4,0 & 187 & 20 & 47 & 3,7 & 176 \\
\hline \multirow[t]{2}{*}{$\mathrm{KCl}$} & 600 & 24 & 66 & 5,7 & 204 & 22 & 52 & 3,6 & 194 & 21 & 50 & 4,0 & 182 \\
\hline & 1800 & 26 & 59 & 6,0 & 217 & 21 & 44 & 3,9 & 199 & 24 & 53 & 4,4 & 206 \\
\hline \multirow[t]{2}{*}{ Kontrol } & 0 & 22 & 65 & 5,6 & 198 & 23 & 80 & 4,8 & 219 & 20 & 49 & 3,9 & 201 \\
\hline & 200 & 22 & 64 & 5,2 & 173 & 20 & 48 & 3,9 & 187 & 20 & 57 & 4,5 & 196 \\
\hline \multirow[t]{2}{*}{ KNO3 } & 600 & 24 & 64 & 5,5 & 176 & 20 & 51 & 3,5 & 176 & 22 & 58 & 4,7 & 199 \\
\hline & 1800 & 24 & 61 & 5,8 & 204 & 21 & 51 & 4,1 & 204 & 22 & 52 & 4,6 & 196 \\
\hline \multirow[t]{2}{*}{ Kontrol } & 0 & 22 & 65 & 5,6 & 198 & 23 & 80 & 4,8 & 219 & 20 & 49 & 3,9 & 201 \\
\hline & 200 & 23 & 64 & 5,3 & 178 & 21 & 52 & 3,5 & 185 & 19 & 54 & 4,4 & 188 \\
\hline \multirow[t]{2}{*}{ K2SO4 } & 600 & 24 & 84 & 5,8 & 206 & 21 & 50 & 3,6 & 191 & 20 & 50 & 4,1 & 189 \\
\hline & 1800 & 25 & 90 & 5,7 & 237 & 24 & 52 & 4,0 & 209 & 22 & 51 & 4,6 & 215 \\
\hline
\end{tabular}




\section{Sonuç}

Farklı potasyum formlarının brokoli yeşil aksamında Cd birikimi üzerine etkilerinde farklılıkların olduğu belirlenmiştir. Toprakların Cd kirlilik düzeylerine göre $\mathrm{K}$ gübrelerinin uygulanması brokoli kuru madde veriminde azaltıcı etkisi saptanmıștır. Kadmiyum kirliliğinin yüksek olduğu topraklarda $\mathrm{KCl}$ formunun $\mathrm{KNO}_{3}$ ve $\mathrm{K}_{2} \mathrm{SO}_{4}$ formlarına göre, kuru madde verimini \%50 oranında azalmasina neden olurken aynı zamanda yeșil aksamda da daha fazla $\mathrm{Cd}$ birikmesine neden olmuștur. $\mathrm{Bu}$ sonuçlar göstermektedir ki artan $\mathrm{KCl}$ dozlarıyla K gübrelemesi sadece topraklardaki $\mathrm{Cd}$ fraksiyonlarını değiștirmekle kalmayıp aynı zamanda brokoli yeşil aksaminda $\mathrm{Cd}$ birikimini de etkimektedir. $\mathrm{Bu}$ nedenle, $\mathrm{Cd}$ kontamine olmuş topraklarda brokoli sebzesinde $\mathrm{Cd}$ birikimini hafifletmek için $\mathrm{KNO}_{3}$ gübresi uygulamak daha akılcı bir yaklaşım olacaktır.

\section{Kaynaklar}

Alloway, B. J. (1995). Heavy Metals in Soils, Chapman\&Hall, London, UK.

Bergman, W. (ed.). (1992). Nutrient disorders of plant development: Visual and analytical diagnosis. Gustav Fischer, New York.

Boussen, S., Soubrand, M., Bril, H., Ouerfelli, K., \& Abdeljaouad, S. (2013). Transfer of lead, zinc and cadmium from mine tailings to wheat (Triticum aestivum) in carbonated Mediterranean (Northern Tunisia) soils. Geoderma, 192, 227-236.

Bouyoucos, G. J. (1962). Hydrometer method improved for making particle size analyses of soils 1. Agronomy journal, 54(5), 464-465.

Cheng, M., Kopittke, P. M., Wang, A., \& Tang, C. (2019). Salinity decreases $\mathrm{Cd}$ translocation by altering $\mathrm{Cd}$ speciation in the halophytic Cd-accumulator Carpobrotus rossii. Annals of botany, 123(1), 121132.

Çağlar, K., \& Bilgisi, T. (1949). Ankara Üniversitesi Ziraat Fakültesi Yayınları No: 10

Esençayı, M. K., \& Korkmaz, K. (2019). Ordu Topraklarının Potasyum Durumu ve Potasyum Fiksasyonunun Belirlenmesi. Türk Tarım ve Doğa Bilimleri Dergisi, 6(4), 878-886.

Fergusson, J. E. (1990). The heavy elements: chemistry, environmental impact adn health effects $\bigvee a c k E$. Fergusson (No. 628.53 F4.).

Huang, Q., Yu, Y., Wan, Y., Wang, Q., Luo, Z., Qiao, Y., \& Li, H. (2018). Effects of continuous fertilization on bioavailability and fractionation of cadmium in soil and its uptake by rice (Oryza sativa L.). Journal of environmental management, 215, 13-21.

Jackson, M. L,. 1959. Soil chemical analysis. Englewood Cliffs, New Jersey.

Järup, L., Berglund, M., Elinder, C. G., Nordberg, G., \& Vanter, M. (1998). Health effects of cadmium exposure-a review of the literature and a risk estimate. Scandinavian journal of work, environment \& health, 1-51.

Jinadasa, K. B. P. N., Milham, P. J., Hawkins, C. A., Cornish, P. S., Williams, P. A., Kaldor, C. J., \& Conroy, J. P. (1997). Survey of cadmium levels in vegetables and soils of Greater Sydney, Australia. Journal of Environmental Quality, 26(4), 924-933.

Korkmaz, K., Özbay Dede, H. E., Çankaya, S., \& Akgün, M. (2015). Relationships between chemical and physical properties of soils and nutrient status of plants on yield of potato. Fresenius Environmental Bulletin, 24(11 C), 4108-4113.

Korkmaz, K., Ertürk, Ö., Ayvaz, M. Ç., Özcan, M. M., Akgün, M., Kirli, A., \& Alver, D. O. (2018). Effect of Cadmium Application on Antimicrobial, Antioxidant and Total Phenolic Content of Basil Genotypes. Indian Journal of Pharmaceutical Education and Research, 52(4), S108-S114.

Kılıç, R., \& Korkmaz, K. (2012). Kimyasal gübrelerin tarım topraklarında artık etkileri. Research Journal of Biology Sciences, 5(2), 87-90.

Lindsay, W. L., \& Norvell, W. (1978). Development of a DTPA soil test for zinc, iron, manganese, and copper 1.Soil science society of America journal, 42(3), 421-428.

Liu, J., Li, K., Xu, J., Liang, J., Lu, X., Yang, J., \& Zhu, Q. (2003). Interaction of $\mathrm{Cd}$ and five mineral nutrients for uptake and accumulation in different rice cultivars and genotypes. Field Crops Research, 83(3), 271281.

Liu, Y., Zhuang, P., Li, Z., Zou, B., Wang, G., Li, N., \& Qiu, J. (2013). Effects of fertiliser and intercropping on cadmium uptake by maize.Chemistry and Ecology, 29(6), 489-500.

McBride, M. B. (2003). Toxic metals in sewage sludgeamended soils: has promotion of beneficial use discounted the risks?. Advances in environmental research, 8(1), 5-19.

McLaughlin, M. J., Andrew, S. J., Smart, M. K., \& Smolders, E. (1998a). Effects of sulfate on cadmium uptake by Swiss chard: I. Effects of complexation and calcium competition in nutrient solutions. Plant and Soil, 202(2), 211-216. 
Mclaughlin, M. J., Andrew, S. J., Smart, M. K., Smolders, E., 1998a. Cadmium uptake by swiss chard:I. Effects on complexation and calcium competition in nutrient solutions. Plant and Soil. 202: 211-216.

McLaughlin, M. J., Andrew, S. J., Smart, M. K., \& Smolders, E. (1998b). Effects of sulfate on cadmium uptake by Swiss chard: I. Effects of complexation and calcium competition in nutrient solutions. Plant and Soil, 202(2), 211-216.

McLaughlin, M. J., Tiller, K. G., \& Smart, M. K. (1997). Speciation of cadmium in soil solutions of saline/sodic soils and relationship with cadmium concentrations in potato tubers (Solanum tuberosum L.). Soil Research, 35(1), 183-198.

Nie, J., Liu, Y., Zeng, G., Zheng, B., Tan, X., Liu, H., ... \& Liu, W. (2016). Cadmium accumulation and tolerance of Macleaya cordata: a newly potential plant for sustainable phytoremediation in Cd-contaminated soil. Environmental Science and Pollution Research, 23(10), 10189-10199.

Norvell, W. A., Wu, J., Hopkins, D. G., \& Welch, R. M. (2000). Association of cadmium in durum wheat grain with soil chloride and chelate-extractable soil cadmium. Soil Science Society of America Journal, 64(6), 2162-2168.

Olsen, S. R. (1954). Estimation of available phosphorus in soils by extraction with sodium bicarbonate (No. 939). US Department of Agriculture.

Özkutlu, F., Özturk, L., Erdem, H., McLaughlin, M., \& Cakmak, I. (2007). Leaf-applied sodium chloride promotes cadmium accumulation in durum wheat grain. Plant and soil, 290(1-2), 323-331.

Özkutlu, F. \& Kara, Ş. M. (2018). The effect of zinc (Zn) fertilization on alleviating cd accumulation in durum wheat grain. Journal of Agricultural Science and Technology B, 8 (2018): 203-208.

Özkutlu, F. \& Kara, Ş. M. (2019). Cd concentration of durum wheat grain as influenced by soil salinity. Akademik Ziraat Dergisi, 8 (1): 97-100.

Salardini, A. A., Sparrow, L. A., \& Holloway, R. J. (1993). Effects of potassium and zinc fertilizers, gypsum and leaching on cadmium in the seed of poppies (Papaver somniferum L.). In Plant Nutrition-from Genetic Engineering to Field Practice (pp. 795-798). Springer, Dordrecht.

Schlichting, E., \& Blume, H. P. (1966). Bodenkundliches Praktikum: Verlag Paul Parey.

Smolders, E. M. J. G., Lambregts, R. M., McLaughlin, M. J., \& Tiller, K. G. (1998). Effect of soil solution chloride on cadmium availability to Swiss chard. Journal of Environmental Quality, 27(2), 426-431.

U. S. Salinity Laboratory Staff., 1954. Diagnosis and improvement of saline and alkaline soils (Ed L. A. Richards). USDA Agriculture Handbook B, No: 60, U. S. Gov. Printing Office, Washington, 160P.

Wang, J., Yuan, J., Yang, Z., Huang, B., Zhou, Y., Xin, J., ... \& Yu, H. (2009). Variation in cadmium accumulation among 30 cultivars and cadmium subcellular distribution in 2 selected cultivars of water spinach (Ipomoea aquatica Forsk.). Journal of agricultural and food chemistry, 57(19), 8942-8949.

Wu, J., Geilfus, C. M., Pitann, B., \& Mühling, K. H. (2016). Silicon-enhanced oxalate exudation contributes to alleviation of cadmium toxicity in wheat. Environmental and Experimental Botany, 131, 10-18.

Zarcinas, B. A., \& Nable, R. O. (1992). Boron and other impurities in South Australian fertilizers and soil amendments. Adelaide, SA, CSIRO Division of Soils.

Zhang, K., Yuan, J., Kong, W., \& Yang, Z. (2013). Genotype variations in cadmium and lead accumulations of leafy lettuce (Lactuca sativa L.) and screening for pollution-safe cultivars for food safety. Environmental Science: Processes \& Impacts, 15(6), 1245-1255.

Zhao, Z. Q., Zhu, Y. G., Li, H. Y., Smith, S. E., \& Smith, F. A. (2004). Effects of forms and rates of potassium fertilizers on cadmium uptake by two cultivars of spring wheat (Triticum aestivum, L.). Environment international, 29(7), 973-978. 